\title{
SANTUÁRIO FABRICADO: UMA TIPOLOGIA E UM ESTUDO DE CASO
}

\author{
Francisco John Lennon Alves Paixão Lima \\ Doutor em Geografia pela Universidade Estadual de Maringá \\ johnlima ce@yahoo.com.br \\ Maria das Graças de Lima \\ Universidade Estadual de Maringá \\ Professora do Departamento de Graduação e de Pós-Graduação em Geografia \\ mglima@uem.br
}

\begin{abstract}
RESUMO
O presente artigo apresenta uma discussão acerca do conceito de santuário fabricado, fruto de quatro anos de pesquisa em curso de doutoramento em Geografia, com foco em Geografia Cultural. A pesquisa tem como área de enfoque a região sul do Brasil, tendo sido catalogados 101 santuários oficiais católicos. Metodologicamente, no que diz respeito a promoção da referida tese de doutoramento, realizou-se um levantamento do quadro de santuários oficiais presentes no sul brasileiro, aplicou-se questionário, fez-se entrevista e pesquisa em sites, artigos e livros. A necessidade de se trabalhar com o referido tema se justifica pela dificuldade de aplicação do conceito de santuário à realidade de alguns espaços sacroprofanos interdependentes (LIMA,2016), com base no código de direito canônico número 1230 e em autores que estudam ou estudaram o conceito de santuário, como Rubert (1987), Santos (2008) e Rosendahl $(1996,2014)$. Percebeu-se que, aos santuários fabricados, é inviável igualá-los conceitualmente a outros complexos sacroprofanos interdependentes: as características são signicamente distintas, desde o movimento de peregrinos à dinamização e organização espacial, ritual e turística do complexo, o que envolve seu espaço de entorno, mas também sua territorialização. Além disso, no santuário fabricado não há peregrinação ou esta ocorre de forma ínfima.
\end{abstract}

Palavras-chave: Santuário Fabricado. Peregrinação. Geografia Cultural.

\section{FABRICATED SANCTUARY: A TYPOLOGY AND A CASE STUDY}

\begin{abstract}
This article presents a discussion about the concept of sanctuary fabricated as a result of four years of research in a PhD course in Geography, with a focus on Cultural Geography. The research focuses on the southern region of Brazil, with 101 official Catholic sanctuaries cataloged. Methodologically, with regard to the promotion of the aforementioned doctoral thesis, a survey of the official sanctuaries present in southern Brazil was carried out, a questionnaire was applied, interviews and research were done on websites, articles and books. The need to work with the aforementioned theme is justified by the difficulty of applying the concept of sanctuary to the reality of some interdependent sacroprofan spaces (LIMA, 2016), based on code of canon law number 1230 and authors who study or have studied the concept of sanctuary, such as Rubert (1987), Santos (2008) and Rosendahl (1996, 2014). It was noticed that, to the fabricated sanctuaries, it is not feasible to equate them conceptually with other interdependent sacroprofan complexes: the characteristics are significantly different, from the movement of pilgrims to the dynamization and spatial, ritual and touristic organization of the complex, which involves their space of surroundings, but also their territorialization. In addition, in the fabricated sanctuary there is no pilgrimage or it happens in a tiny way.
\end{abstract}

Keywords: Fabricated Sanctuaries. Pilgrimage. Cultural Geography.

\section{INTRODUÇÃO}

O presente artigo apresenta uma discussão objetiva acerca do conceito de santuário fabricado, conceito desenvolvido por Lima (2020, no prelo) em estudo sobre os santuários católicos oficiais localizados na região sul do Brasil e que brevemente será apresentado em formato de tese em curso de doutoramento em

$\begin{array}{lllll}\text { Caminhos de Geografia } \quad \text { Uberlândia-MG } & \text { v. 21, n. } 78 \quad \text { Dez/2020 } & \text { p. 36-47 Página } 36\end{array}$


Geografia, estando focado no arcabouço da Geografia Cultural. A tese trabalha centralmente com santuários católicos oficiais e analisa sua influência em seu espaço geográfico de entorno, seu papel na economia local, bem como sua relação com o desenvolvimento de seu lócus, com base no conceito de desenvolvimento urbano de Souza (2005), além dos significados que estes possuem no repensar conceitualmente a categoria santuário mediante a capacidade que estes espaços sacroprofanos possuem no cumprimento de sua função religiosa (FRANÇA, 1975). A tese apresenta, portanto, uma discussão sobre santuários oficiais comuns e santuários oficiais fabricados ou, simplesmente, santuários fabricados. Por outro lado, neste artigo, o foco será dado ao conceito de santuário fabricado como forma de facilitar sua compreensão enquanto aplicabilidade e terá sua materialidade embasada em um exemplo prático de campo. A necessidade de se trabalhar com esse tema emergiu da dificuldade de adequação prática de alguns santuários católicos oficiais analisados durante trabalho de campo e em pesquisa exploratória ao conceito canônico de santuário, principal referência de identificação destes espaços para a Igreja Católica. E mesmo quando assumido autores da Geografia e de outras ciências, como da Sociologia, no pensar conceitualmente santuário, a problemática se instala: as diferenças estruturais, as características materiais, as motivações ao surgimento e manutenção desses espaços, bem como sobre o movimento de peregrinos são notórios, o que reforçou a ideia de que uma revisão conceitual seria necessária a adequação de determinados espaços sacroprofanos cujo cumprimento de sua função religiosa não ocorre: por não ser um espaço em que a mescla entre sagrado e profano ocorre e um conjunto de elementos basilares na vida de um santuário não se faz presente, como possuir uma sala dos milagres, hierofanias e um contexto místico numa verdadeira dinâmica de acolhida e de atração de peregrinos.

As cidades que possuem santuários oficiais católicos, a depender de sua qualidade enquanto espaço de aglomeração de peregrinos, podem ser compreendidas, com base em Rosendahl (2014, p. 209), como verdadeiras hierópolis, "[...] cidades que possuem uma ordem espiritual predominantemente marcada pela prática religiosa da peregrinação ou romaria ao lugar sagrado". Do ponto de vista da Geografia, a peregrinação é o elemento mais importante na dinâmica dos santuários, caracterizando-se como uma migração temporária em prol do bem estar espiritual do peregrino. Contudo, para além da peregrinação, durante o trabalho de campo relativo à referida tese, foram identificados pelo menos quatro elementos geográficos que se apresentam como característicos do santuário do tipo oficial comum: peregrinação, lugar turístico, espaço sagrado e paisagem sacra. Esses elementos compõem o que na tese se intitulou de critérios de definição de santuário, dados característicos inerentes à realidade esperada de um santuário oficial comum, com base na aglutinação de variados conceitos de santuário levantados na referida tese de doutoramento. Ainda sobre a peregrinação, principal elemento de identificação de um santuário, o ato de peregrinar, segundo Santos (2010), consiste numa realidade multidimensional interpretada em diferentes perspectivas, um patrimônio cultural praticado a partir de várias motivações e intenções, [...] "desde a experiência mística até a busca da resolução das mais básicas necessidades materiais" (2010, p. 149). A autora acrescenta ainda que, antes de tudo, peregrinar é a [...] "expressão de uma busca espiritual que, conquanto se exprima exteriormente, é sobretudo uma demanda interior" (2010, p. 147). Já Stoddard (1997, p. 49 apud Santos, 2010, p. 177) apresenta a peregrinação como sendo um [...] "evento que consista numa deslocação que ultrapasse o nível local, efetuada por numerosas pessoas em direção a um lugar sagrado, como um ato de devoção religiosa".

Os critérios de definição de santuário (Quadro 1), como mencionado, foram levantados a partir do estudo de vários conceitos de santuário, o que abrangeu não só a ciência Geografia, mas também a História, a Sociologia e a Teologia, neste caso com o uso do código do direito canônico católico. Após o levantamento dos conceitos, estes foram comparados uns aos outros a fim de identificar perfis análogos que pudessem gerar um entendimento geral acerca das características dos santuários estudados e assim separar aqueles santuários que conceitualmente se aplicam junto aos autores daqueles que extrapolam tal realidade. $\mathrm{O}$ surgimento do conceito de santuário fabricado aparece exatamente nesse momento de problematização da amostragem a partir dos critérios de definição de santuário com a realidade sócio espacial dos complexos sacroprofanos interdependentes. Além disso, os santuários fabricados extrapolam o conceito canônico e de vários autores de tal forma que se torna inviável igualá-los conceitualmente a outros complexos sacroprofanos: as características são signicamente distintas, no que diz respeito ao movimento massivo de peregrinos, a dinamização e organização espacial, ritual e turística envolvendo seu lócus, sua caracterização (material e imaterial) e as marcas do sagrado no espaço, bem como sua infraestrutura.

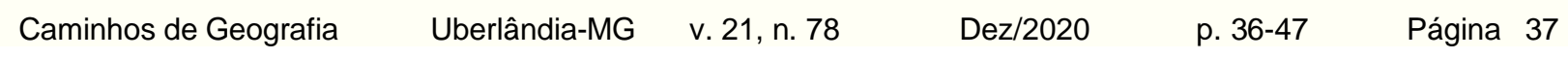


Quadro 1 - Critérios de definição de santuário.

\begin{tabular}{l}
\hline 1 - Espaço de peregrinação/procissão/romaria \\
\hline 2 - Ocorrência de Milagre/Aparição \\
3 - Existência de relíquias (objetos sagrados) \\
4 - Estrutura arquitetônica/pintura/escultura (Paisagem Sacra) \\
5 - Festa religiosa \\
6 - Ex-votos \\
7 - Lugar turístico \\
8 - Igreja ou outro espaço sagrado \\
9 - Sala dos milagres.
\end{tabular}

Fonte - do autor (2019).

Uma das observações presentes junto à tese consiste no entendimento de que, na prática, não há uma preocupação adequada por parte dos agentes do sagrado em elevar ou criar santuários que estejam, de fato, engajados nos preceitos conceituais adequados à formação de santuários, que no caso da Igreja Católica cabe ao reconhecimento do código de direito canônico. Por isso o surgimento de estruturas estranhas.

Durante a produção do trabalho de campo da tese, alguns santuários se apresentaram como santuários fabricados e outros como santuários oficiais comuns. Foram, ao todo, 101 santuários catalogados distribuídos nos três estados da região sul do Brasil, porém em 14 foram realizados trabalhos de campo. Será, assim, utilizado como referência neste artigo o Santuário Nossa Senhora de Fátima, localizado na cidade de Campina Grande do Sul, Paraná, como exemplo de santuário do tipo fabricado. Quando necessário, utilizar-se-á o santuário oficial comum de Nossa Senhora do Rocio, localizado na cidade de Paranaguá-PR, como contraponto à experiência do santuário fabricado. Ambos compõem a amostra trabalhada em campo. Espera-se, assim, que este artigo, juntamente à tese, que será defendida em breve, sirva de inspiração e motivação ao surgimento de novos trabalhos na temática.

\section{METODOLOGIA}

A metodologia utilizada para promoção deste artigo pautou-se basicamente de uma sistematização dos dados e resultados proveniente da tese de doutoramento a ser defendida, porém priorizando apresentar 0 conceito de santuário fabricado. Já para a promoção dos dados e resultados da tese utilizados neste artigo foram catalogados 101 santuários distribuídos pela região sul do Brasil e utilizada a Internet como fonte de pesquisa (santuário por cidade/estado da referida região), bem como artigos e livros visando a conceituação do termo santuário. Após o levantamento do quantitativo de santuários, buscou-se em sites e por meio de chamada de voz (telefone) e aplicação de questionário a confirmação dos referidos espaços sacroprofanos interdependentes como santuários oficiais, bem como aplicado um questionário prévio com representantes de cada santuário contendo perguntas inerentes aos critérios de definição de santuário, como forma de captar quantos critérios aquele determinado santuário possui em seu arcabouço. Uma vez possuindo a lista de santuários catalogados, foram selecionados 14 complexos à promoção do campo prático, momento em que se vislumbrou na prática o comportamento e as características de cada santuário, bem como sua relação com o seu espaço de entorno. Antes disso, fora realizado campo em três outros santuários como estratégia ou teste metodológico de campo, no que Gil (2008) chama de "Pesquisa Exploratória". A razão para esse tipo de pesquisa de cunho exploratório é a de desmistificar impressões pré-estabelecidas e gerar uma visão mais geral acerca do objeto de estudo. Em outras palavras, é um primeiro olhar sobre aquilo que se está investigando.

A lista contendo os 14 santuários objetivou mostrar na prática a existência de espaços denominados de santuários fabricados, espaços sacroprofanos interdependentes oficiais, portanto reconhecidos pela lgreja Católica, mas que não atendem aos requisitos mínimos de definição de santuário, como por exemplo: peregrinação, que pode está atrelada a um fator milagroso que justifique a criação ou emancipação daquele determinado espaço em um santuário; ocorrência de ex-votos; paisagem sacra como um conjunto de símbolos religiosos e de expressividade do sagrado, algo que atribua destaque do fato em si; turismo religioso, dentre outros. Somada a esses elementos, a sala dos milagres, como termômetro qualitativo do santuário e do(a) santo(a) padroeiro(a), com base em Pereira (2003), também compõe a lista de critérios de definição de santuário (vide Quadro 1) e se apresenta como elemento importante na aferição qualitativa do

$\begin{array}{lllll}\text { Caminhos de Geografia } \quad \text { Uberlândia-MG } & \text { v. 21, n. } 78 \quad \text { Dez/2020 } & \text { p. 36-47 Página } 38\end{array}$


santuário. Dos nove critérios de definição de santuário, quatro são de cunho geográfico e possuem, para essa ciência, uma importância destacada. São eles: peregrinação, lugar turístico, paisagem sacra e espaço sagrado. Uma vez conquistados os dados de campo, somados às informações obtidas através da pesquisa exploratória e via internet, artigos e livros específicos, fez-se a problematização e construção dos relatórios à confecção da referida tese e, consequentemente, deste artigo.

\section{RESULTADOS E DISCUSSÃO}

De acordo com os dados coletados em campo, com as leituras acerca do conceito de santuário e com a problematização das informações resultantes dos questionários, as motivações observadas à elevação de espaços sagrados, de paróquias suficientes (que possuem, sustentam e emanam características de paróquia) e de outros componentes na hierarquia dos templos católicos a santuário, nos dias atuais, são variadas: pelo desejo particular dos agentes ou do agente do sagrado, seja padre ou bispo; por motivação popular; pelo desejo da administração da cidade de transformar um espaço de reflexão e oração em um espaço que privilegie o turístico religioso, o que poderia resultar em um maior investimento em infraestrutura do entorno e do próprio complexo ao cumprimento das atividades do sagrado, mas também como influência na atividade econômica da cidade; por apelo místico religioso em que um(a) santo(a) é tido(a) como provedor(a) de milagres e elemento significante de atração de peregrinos; de forma natural, ganhando "corpo" com o passar do tempo, muito em função da participação e visitação de fiéis romeiros/peregrinos motivados, sobretudo, pela fama milagrosa do ser devotado; e também por necessidade de reforma do santuário onde, por improviso, enquanto os agentes do sagrado investem numa infraestrutura adequada ao local, um espaço insuficiente toma signicamente a forma de santuário. Estes são os fatores encontrados nesta pesquisa à elevação de estruturas sagradas em espaços sacroprofanos interdependentes (LIMA, 2016), sejam oficiais comuns ou fabricados. A principal diferença entre ambos os tipos de santuários está em seu papel diante da função religiosa a ser cumprida. O santuário fabricado, apesar de oficial, ou seja, de ser reconhecido pela Igreja Católica, não cumpre com sua função religiosa de ser efetivamente um espaço de acolhida de peregrinos e de comemorações festivas, como nos mostra Rosendahl (1999) e França (1975), e de aproximação do indivíduo religioso a um ser superior (ELIADE, 1992), que, mormente, trata-se de um santo padroeiro (no centro do mundo), assim como de ser um espaço de reencontro de familiares e amigos (LIMA, 2016), que aproveitam o ato de migrar (temporariamente) como mecanismo de reencontro e de dinamismo econômico, onde o sagrado torna-se motivação e mercadoria e o profano um suporte e condição à existência dessa conjuntura. Em muitos casos, quando o indivíduo religioso mora em outra cidade, é mais conveniente e simbolicamente representativa a ida dele até sua cidade natal para contemplação de uma festa ou ritual sagrado de um santo ou santa padroeira do que necessariamente num período de convenção social aleatório, isso porque a peregrinação constitui, além de um ato de misericórdia, uma forma de visitar parentes e amigos. Como se diz no popular: "é unir o útil ao agradável".

Todo santuário católico atual deve ser visto como um espaço sacroprofano interdependente (LIMA, 2016), ou seja, nele ocorre e se faz necessária uma relação entre espaço sagrado e espaço profano, com base em Rosendahl (1997), no intuito de cumprimento de suas atividades sagradas. Pelo fato de não haver uma imbricação consistente entre esses dois espaços no contexto do santuário fabricado, justificado pela pusilanimidade dos serviços e do comércio que caracteriza o espaço profano dentro da relação sacroprofana, esse tipo de santuário possui uma interdependência sacroprofana incompleta ou irrelevante, o que dificulta seu crescimento e manutenção no tempo e no espaço. Atualmente é fundamental que o santuário possua uma relação de interdependência sacroprofana consistente que permita uma dinamização de suas atividades e de seu complexo capaz de fomentar seu crescimento em direção àquilo que se compreende como santuário oficial comum nos dias atuais.

É no cumprimento e na caracterização da função religiosa desses espaços que o santuário pode ser identificado como santuário oficial comum ou santuário fabricado: ambos os tipos de santuários são oficiais, ou seja, reconhecidos pela Igreja Católica, com base no código de direito canônico 1230, mas suas características são signicamente distintas. De acordo com o código de direito canônico 1230, a denominação de santuário refere-se a uma igreja ou qualquer outro lugar sagrado na qual os fiéis, em grande número e por algum motivo de piedade, fazem peregrinações com a aprovação do representante local (agente do sagrado). Esse conceito canônico é a base de entendimento da oficialidade dos santuários católicos para a Igreja, ou seja, a oficialidade do santuário independe da qualidade ou das características pertinentes ao específico santuário, mas de sua visibilidade e intencionalidade perante a Igreja. $\mathrm{O}$ que se percebeu no desenvolvimento da tese é que, infelizmente, esse entendimento por parte da lgreja acaba elevando determinados espaços religiosos à categoria de santuário oficial sem necessariamente estes 
espaços possuírem as características básicas de santuário, como o de ser um espaço de atração de peregrinos. É, portanto, dessa problemática que surgem os santuários fabricados, pois, afinal, a base de compreensão centra-se sobre o critério "peregrinação": se há peregrinos, há um espaço sagrado reconhecido para além do local, consequentemente será organizado um tipo de turismo voltado à religiosidade e formada/ampliada, ao longo do tempo, uma paisagem sacra, ou seja, simbólica religiosa, além da venda de lembrancinhas. Pode ser instalado também restaurantes, dormitórios, estacionamentos, agências de viagem, etc., o que afeta diretamente a realidade da cidade lócus. Um Santuário Fabricado não possui essa dinâmica, pois não ocorre peregrinação ou esta se da de forma ínfima, logo seu espaço sagrado é reconhecido apenas localmente, não há sentido no turismo religioso, mesmo havendo formação de paisagem sacra. Além disso, a territorialidade do sagrado, no caso do Santuário Fabricado, limita-se a proximidade do templo e/ou da cidade, a depender de seu tamanho. O oposto ocorre no caso do santuário oficial comum, sua territorialidade pode ir além das fronteiras nacionais, dependendo de sua qualidade, da aceitação do ser devotado e da organização do complexo por parte dos agentes do sagrado.

Um santuário fabricado representa, em alguns casos, o fracasso do espaço dito sagrado pela não presença de peregrinos, seu principal elemento identitário, mas também pela criação sem controle ou rigidez de novos santuários por parte dos agentes do sagrado e, assim, desconsiderando a necessidade de cumprimento da função religiosa do complexo. Alguns espaços são simplesmente elevados à categoria de santuário pelo simples desejo particular de seu pároco: às vezes por um vislumbre imagético pessoal ou simples desejo de ver sua comunidade ampliada (territorialidade do sagrado).

No desenvolvimento da tese vários conceitos de santuários foram analisados para que fosse possível estabelecer uma relação entre eles e assim estipular determinados elementos ou critérios que pudessem servir como critérios de definição de santuário, dados característicos comuns e, portanto, esperados por qualquer santuário. Buscou-se, assim, problematizar o conceito de santuário empregado nas ciências humanas, com base nas obras de alguns autores, de forma a constatar sua aplicabilidade no atual quadro de santuários católicos foco da pesquisa, discutindo, assim, sua implicação espacial, social e econômica, bem como seus significados mediante a devida coerência conceitual em que se aplica. É importante salientar que por se tratar de santuários católicos oficiais, o conceito canônico de santuário representa, assim, a base de coerência ou orientação conceitual à Igreja. Porém, para a Geografia, são os critérios de definição de santuário os elementos identificadores destes espaços, assim como os responsáveis pela variabilidade prática no identificar do santuário. Dentre os conceitos de santuário analisados à formação dos critérios de definição de santuário, podemos citar Lima (2016, p. 24): o autor apresenta o santuário como "[...] um complexo dinâmico e interdependente que engloba serviços e comércio articulados ao ofício religioso"; Por outro lado, Rosendahl (1996, p. 45) trata do conceito de cidade santuário ou hierópolis, "[...] centros de convergência de peregrinos que com suas práticas e crenças, materializam uma peculiar organização funcional e social do espaço"; Já Santos (2008, p. 2) classifica os santuários como lugares sagrados ou igrejas "[...] sempre que neles concorram dois requisitos expressamente previstos em termos jurídico-canônicos: o fato de eles ocorrerem multidões de fiéis em peregrinação e o de serem objeto de aprovação por parte do respectivo bispo diocesano". A autora afirma também que "[...] um santuário distingue-se de outros lugares religiosos por se reconhecer que aí está presente um grau mais elevado de sacralidade, independentemente da forma concreta que esta se manifeste" (SANTOS, 2008, p. 2); Rubert (1987) apresenta pelo menos quatro características consideradas importantes e singulares no tratamento conceitual de santuário: transitoriedade, expectativa, universalidade e peregrinação. Essas quatro condições representam a plenitude de qualquer santuário, na forma como a Igreja compreende. Nas palavras do próprio autor, o santuário

[...] em nada se distingue de outra igreja. Possui as mesmas características duma igreja comum para as pessoas que vivem ao seu redor e dele participam regularmente. No entanto, o Santuário possui algumas características peculiares, que são importantes também para sua vida litúrgica. Em primeiro lugar, o Santuário se caracteriza por ser um lugar de peregrinação pela transitoriedade das pessoas e grupos que o frequentam. As assembleias que chegam a se formar no Santuário também são transitórias, adquirindo conotações peculiares de um grupo humano transitório, peregrino. Essa dimensão distingue o Santuário. Em segundo lugar, o Santuário se caracteriza pela universalidade, isto é, por ser um lugar aberto a todos. Essa realidade o faz viver na constante expectativa, na incerteza, na provisoriedade, mas também na beleza da novidade (RUBERT, 1987, p. 25).

Outro conceito de santuário analisado à formação dos critérios de definição de santuário foi o conceito de Santos (2008). Segundo a autora, um santuário, espaço de acolhida de peregrinos, possui uma singularidade especial que é a de ser considerado um paraíso perdido, um lugar simbólico detentor de um 
significado próprio e singular. Esse significado age como elemento de atração e dá origem às peregrinações. A partir da intensificação da experimentação dessa singularidade simbólica, o valor sígnico do lugar é reforçado tornando seu caráter de sacralidade mais robusto, isso fortalece também a qualidade do lugar em termos de santidade (SANTOS, 2008).

Com base em França (1975), Rosendahl (1999) e Lima (2016), é na busca de satisfação espiritual e festiva do devoto, de aproximação do ser divino e pelo reencontro com amigos e familiares, no período das festividades do(a) padroeiro(a), que se materializa a função religiosa dos santuários. O santuário fabricado não cumpre com estes preceitos.

Segundo França (1975, p. 11), uma cidade de função religiosa consiste numa cidade "[...] congestionada continua ou periodicamente por uma população flutuante de devotos em busca de satisfação espiritual e atraída pelo ritual das grandes comemorações festivas". As cidades de função religiosa, cidades-santuário ou hierópolis, para Rosendahl (1996, p. 45), "“...] são centros de convergência de peregrinos que com suas práticas e crenças, materializam uma peculiar organização funcional e social do espaço". Esta organização pode ser temporária ou fixa, com base no calendário religioso e do aporte sagrado motivador de peregrinações. Os santuários fabricados correspondem àqueles espaços sacroprofanos de interdependência incompleta que oficialmente são reconhecidos como santuário, mas não possuem uma função religiosa consistente, ou seja, sua função religiosa (FRANÇA, 1975) não se realiza ou não se realiza por completa, sobretudo no que diz respeito às peregrinações, caracterizando-se como inexistentes ou pouco relevantes; podem possuir ou não o fator milagroso de criação que justifique sua existência, como "aparições" ou testemunho de milagre proveniente de alguma entidade sagrada (um santo, por exemplo), isso porque o que importa é o quão abrangente sua sacralidade se faz no espaço por meio de sua territorialidade, ou seja, do alcance de fiéis. Alem disso, ainda sobre o santuário fabricado, a inexistência de um elemento impulsionador pode influenciar diretamente no desempenho de seu complexo; suas atividades são encorajadas à aceitação do povo; o quesito peregrinação é incipiente, o turismo religioso não se aflora, assim como o comércio ligado ao sagrado. Dessa forma, sua participação no viés econômico é mínima ou inexistente e sua capacidade de transformação do espaço geográfico é limitada. Pelo fato de não haver uma imbricação consistente entre os serviços e o comércio que caracteriza o espaço profano dentro da relação sacroprofana do santuário fabricado, este espaço possui uma interdependência sacroprofana incompleta e/ou irrelevante, o que dificulta seu crescimento e manutenção no tempo e no espaço. É fundamental que o santuário possua uma relação de interdependência sacroprofana consistente que permita uma dinamização capaz de fomentar seu crescimento em direção àquilo que se compreende como santuário oficial comum nos dias atuais, um espaço sacroprofano interdependente de acolhida de peregrinos. $́$ É importante mencionar também que um santuário fabricado pode metamorfizar-se na prática em oficial comum, a depender de seu gerenciamento ao longo do tempo ao cumprimento de sua função religiosa. Em suma, um santuário é, sobretudo, um lugar simbólico, porém "[...] não é meramente descoberto, fundado ou construído. Ele é reivindicado, possuído e operado pela comunidade religiosa" (ROSENDAHL, 2014, p. 203).

Como explicado, a necessidade de se trabalhar com o referido tema justificou-se pela dificuldade de aplicação do conceito de santuário oficial católico à realidade de alguns espaços sacroprofanos interdependentes (LIMA,2016) localizados na região sul do Brasil, com base no código de direito canônico número 1230 e a partir de autores que estudam ou estudaram o conceito de santuário, como Rubert (1987), Santos (2008) e Rosendahl $(1996,2014)$ ou mesmo Pereira (2003) que aborda o conceito de centro de devoção, um espaço de acolhida de fiéis à prática da devoção sem necessariamente se tratar de um espaço sacroprofano oficialmente reconhecido pela Igreja. Percebeu-se, assim, que os santuários fabricados extrapolam o conceito canônico de santuário e de muitos autores de tal forma que se torna inviável igualálos conceitualmente a outros complexos sacroprofanos interdependentes. As características são signicamente distintas e visivelmente percebidas, no que se refere ao movimento de peregrinos, à dinamização e organização espacial, ritual e turística do complexo, o que envolve seu espaço de entorno, mas também sua territorialização. A principal característica do santuário fabricado é a sua insuficiência enquanto espaço de atração de peregrinos: não há peregrinação ou esta ocorre de forma muito tímida sem representar movimento significante de peregrinos capaz de dinamizar e influenciar econômica e turisticamente estes espaços. Além disso, a caracterização e as marcas do sagrado no espaço são mínimas, portanto a paisagem sacra dos santuários fabricados é ínfima em termos quantitativos, bem como sua infraestrutura é inadequada à realização de atividades ao cumprimento de sua função religiosa.

Dentre os 14 santuários analisados no trabalho de campo, tem-se o Santuário Nossa Senhora de Fátima, localizado na cidade de Campina Grande do Sul, Paraná, como exemplo de santuário do tipo fabricado. O Santuário de Nossa Senhora de Fátima, pode-se dizer, foi o santuário que mais chamou atenção do pesquisador, dentro do rol de santuários selecionados para o trabalho de campo. As razões para isso são: o santuário, enquanto espaço físico adequado, simplesmente não existe; o templo (Figura1) está em

$\begin{array}{lllll}\text { Caminhos de Geografia } \quad \text { Uberlândia-MG } & \text { v. 21, n. } 78 \quad \text { Dez/2020 } & \text { p. 36-47 } & \text { Página } 41\end{array}$


reforma há cerca de 10 anos e não há movimento de peregrinos em visita espiritual ou turística. Por conta da inexistência do espaço físico adequado, as missas e demais atividades do sagrado são realizadas em um anexo do santuário, um espaço secundário/temporário (Figura2). Entretanto, durante o período da festa da padroeira, as atividades ocorrem no templo central, mesmo estando ainda em reforma.

Figura1 - Santuário Nossa Senhora de Fátima (Templo): Campina Grande do Sul, 2019.

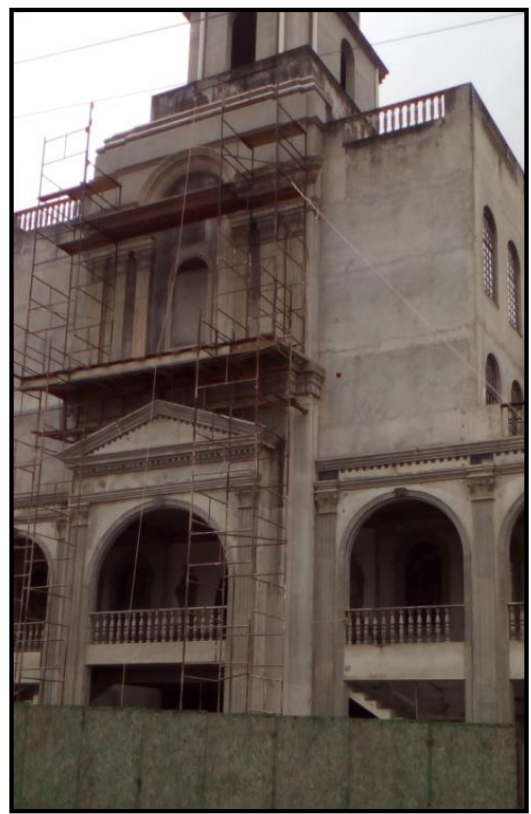

Fonte - do autor (2019).

Figura2 - Santuário Nossa Senhora de Fátima (Anexo): Campina Grande do Sul, 2019.

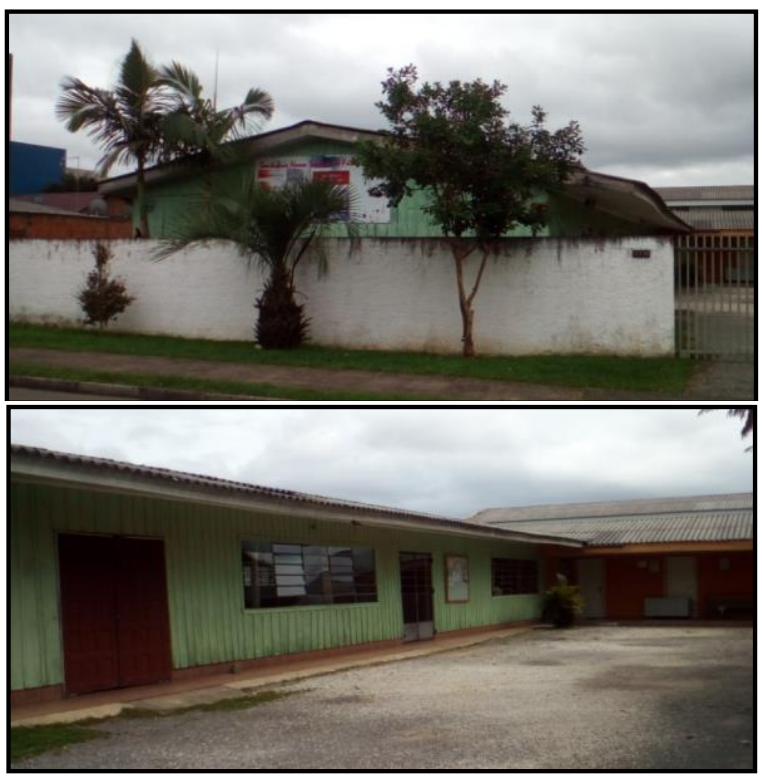

Fonte - do autor (2019).

Do ponto de vista estrutural, este espaço secundário lembra uma escola do primário ou uma creche onde se deixam os filhos para estudar enquanto os pais estão ocupados com seus afazeres. Por se tratar de um espaço improvisado, não há estrutura adequada que comporte aquilo que chamamos de critérios de definição de santuário, ao menos aqueles elementos mais tangíveis, como os ex-votos e a sala dos milagres. O fato de não haver peregrinação por si só já torna este espaço um santuário do tipo fabricado, pois não cumpre com sua principal função religiosa.

$\begin{array}{lllll}\text { Caminhos de Geografia } & \text { Uberlândia-MG } & \text { v. } 21, \text { n. } 78 & \text { Dez/2020 } & \text { p. 36-47 }\end{array}$ Página 42


O anexo ou espaço secundário do santuário é o único espaço atualmente existente destinado à realização das atividades do sagrado neste referido santuário e é relevante informar que não há previsão à utilização da nova estrutura. Por conta dessa limitação física e pela falta de atratividade, enquanto espaço de visitação, a festa da padroeira reúne pouquíssimas pessoas, pois o elemento cênico do templo oficial e, sobretudo, sagrado, não está completo e operante cotidianamente, apesar de ser utilizado no período da festa. Além disso, segundo informações de moradores entrevistados (2019) e da secretaria do santuário por via telefônica (2019), a participação de devotos na festa da padroeira é proveniente da população local, sendo a peregrinação, portanto, um elemento ausente. Em outras palavras, o Santuário de Fátima de Campina Grande do Sul, Paraná, como mencionado, não recebe peregrinos e depende dos moradores locais como núcleo de fiéis. É o completo oposto do que ocorre no Santuário de Nossa Senhora do Rocio (Figura3), em Paranaguá, Paraná. Neste complexo, a devoção à padroeira remonta do século XVII e desde então romarias são realizadas em direção àquela cidade. Do ponto de vista estrutural, o Santuário do Rocio conta com diversos elementos como sala dos milagres, praça dos romeiros, local para queima de velas, uma loja de artigos religiosos, um templo "majestoso" suficiente para o cumprimento de suas atividades, além do complemento oferecido pela própria cidade com restaurantes, hotéis e um ensejo turístico que mistura elementos do cotidiano à conjuntura do sagrado.

Figura3 - Santuário Nossa Senhora do Rocio: Paranaguá, 2019.

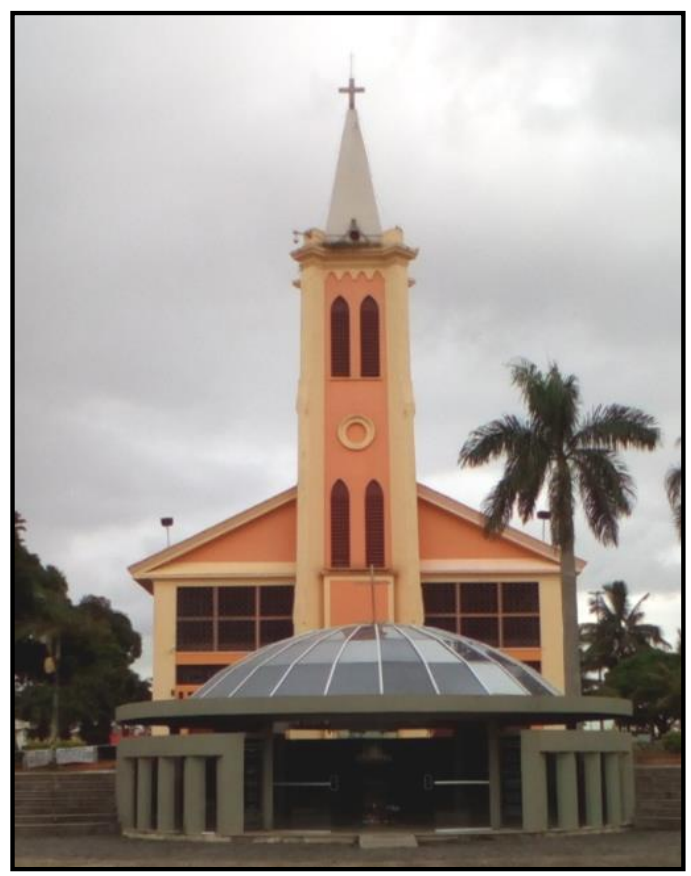

Fonte: do autor (2019).

Do ponto de vista dos critérios de definição de santuário, o santuário de Nossa Senhora do Rocio apresenta todos os nove critérios (Vide quadro 1): trata-se, portanto, de um santuário do tipo oficial comum. Para a Igreja Católica, o reconhecimento enquanto oficialidade, mas para o campo científico geográfico, são os critérios de definição de santuário, com ênfase no critério de peregrinação, que garantem que a função religiosa de um determinado santuário está sendo cumprida e, assim, identificam aquele complexo como santuário.

Como já mencionado, além destes dois santuários, outros 12 foram trabalhados em campo durante a produção da tese de doutoramento da qual este artigo está embasado. Identificou-se, assim, tanto santuários oficiais comuns, como santuários oficiais fabricados, cada um com suas específicas características. Na tabela a seguir (Tabela1), apresentam-se os santuários que foram constatados como oficiais comuns e oficiais fabricados, além de suas respectivas localidades. 
Tabela1 - Santuários Oficiais Comuns e Fabricados observados em campo, 2019.

\begin{tabular}{|c|c|}
\hline Santuários Oficiais Comuns & Localidade \\
\hline Santuário de Nossa Senhora Aparecida & Londrina, Paraná \\
\hline Santuário Nossa Senhora do Rocio & Astorga, Paraná \\
\hline Santuário Nossa Senhora Aparecida & Mafra, Santa Catarina \\
\hline Santuário Nossa Senhora Aparecida & Brusque, Santa Catarina \\
\hline Santuário Nossa Senhora de Azambuja & Caibi, Santa Catarina \\
\hline Santuário Nossa Senhora da Salete & Nonoai, Rio Grande do Sul \\
\hline Santuário Nossa Senhora da Luz e dos Beatos Manuel e & Pdílio \\
\hline Santuário Nossa Senhora Aparecida & São Leopoldo, Rio Grande do Sul \\
\hline Santuário Sagrado Coração de Jesus (Padre Reus) & Novo Hamburgo, Rio Grande do Sul \\
\hline Santuário de Schoenstatt & Guarani das Missões, Rio Grande do Sul \\
\hline Santuário Nossa Senhora Czestochowa & Localidade \\
\hline Santuários Fabricados & Campina Grande do Sul, Paraná \\
\hline Santuário Nossa Senhora de Fátima & Umuarama, Paraná \\
\hline Santuário Nossa Senhora do Perpétuo Socorro & Lages, Santa Catarina \\
\hline Santuário Nossa Senhora de Fátima &
\end{tabular}

Fonte - do autor, 2019.

Como é possível perceber, 11 santuários foram constatados como santuários oficiais comuns e estão distribuídos pelos três estados da região sul do Brasil. Apenas três santuários foram constatados como santuários fabricados, ou seja, são santuários oficiais, portanto reconhecidos pela Igreja Católica, porém fabricados, que não apresentam os critérios de definição de santuário necessários ao cumprimento de sua função religiosa, especialmente os critérios geográficos, com ênfase no critério de peregrinação. Estes santuários existem enquanto oficialidade, porém, na prática, não funcionam como tais, mas como paróquias convencionais: realizam todas as atividades típicas de paróquia e o seu corpo religioso é composto basicamente de moradores da cidade lócus do santuário, ou seja, não há presença de peregrinos.

No Santuário de Fátima de Campina Grande do Sul, Paraná, mais especificamente em seu anexo, há uma pequena gruta artificial (Figura4) contendo uma imagem de Nossa Senhora de Fátima e que serve de lugar de oração. Por sua importância, o anexo é chamado de "Gruta".

Figura4 - Gruta artificial: Campina Grande do Sul, 2019.

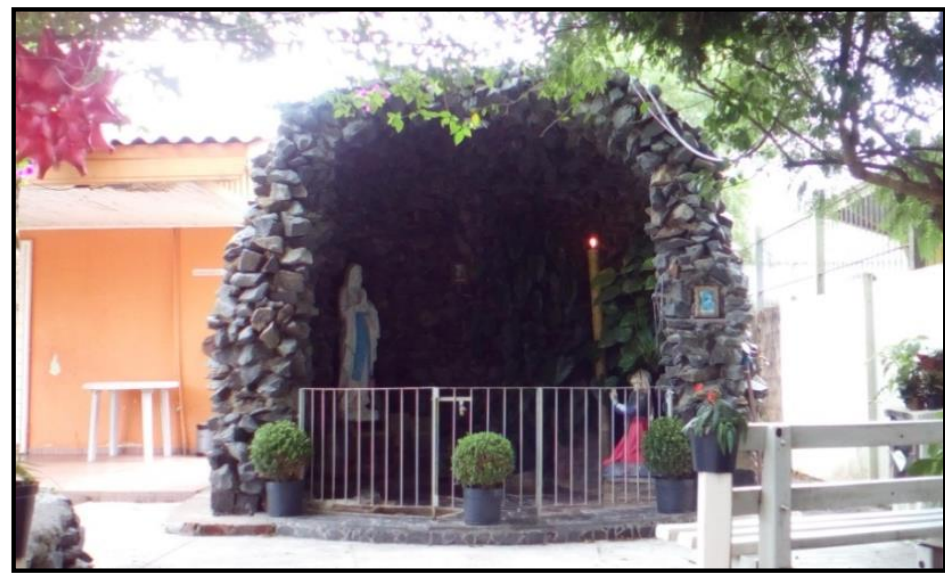

Fonte - do autor (2019).

Segundo informações coletadas via entrevista com populares e com morador responsável pela manutenção do anexo (2019), antes de se tornar palco das atividades do sagrado, o anexo era um "terreno baldio" que fora doado à Igreja por uma moradora local. Entretanto, não fora construído com essa finalidade. Além disso, por possuir uma estrutura que se assemelha à de uma creche estudantil, torna-se difícil reconhecer o lugar 
visivelmente como santuário quando do primeiro contato com aquela realidade, isso porque a paisagem sacra exige destaque do fato em si e isso não ocorre nesse santuário.

Através dos dados coletados durante a pesquisa no santuário de Fátima foi possível identificar a presença ou não dos critérios de definição de santuário (Tabela2), como segue na tabela a seguir.

Tabela2 - Critérios de definição do Santuário de Fátima: Campina Grande do Sul, 2019.

\begin{tabular}{|l|c|l|c|}
\hline \multicolumn{1}{|c|}{ Critério } & Há & \multicolumn{1}{c|}{ Critério } & Há \\
\hline 1- Espaço de peregrinação & & 6 - Ex-votos & \\
\hline 2 - Ocorrência de Milagre & & 7- Lugar turístico & $\mathrm{X}$ \\
\hline 3 - Objetos sagrados & $\mathrm{X}$ & 8- Espaço sagrado & \\
\hline 4 - Paisagem sacra & & 9 - Sala dos milagres. & \\
\hline 5 - Festa religiosa & $X$ & Obs.: Critério de Geograficidade em negrito \\
\hline
\end{tabular}

Como é possível verificar através da tabela acima, seis dos nove critérios não existem nesse santuário, sendo eles: peregrinação, sala dos milagres, ex-votos, paisagem sagra como esculturas e imagens, lugar turístico (percebeu-se que, a posteriori da confecção da tese de doutoramento, neste específico caso, a opção "lugar turístico" fora marcada equivocadamente na tabela de critérios de definição de santuário. Neste artigo, faz-se a devida correção) e ocorrência de um fator místico/milagroso como motivação à formação do santuário em sua gênese. O fato do templo principal está passando por reforma há quase uma década e do espaço atual dedicado às atividades do sagrado ser um espaço incompatível com a necessidade de qualquer santuário, do ponto de vista estrutural, somado à falta desses seis critérios e agravado pela inexistência do critério peregrinação, a essência como resposta a motivação à devoção na realidade de um santuário, torna esse espaço um santuário do tipo fabricado. Apesar disso, o Santuário de Fátima de Campina Grande do Sul é reconhecido como oficial perante a Igreja, mas fabricado por não cumprir com sua função religiosa. O fato de receber apenas fiéis locais o associa a ideia de paróquia ou capela. Ou seja, mostra que não há necessidade de sustentar um título de santuário. Mais do que isso, aponta para uma "má criterização" no ato de elevação à categoria de santuário por parte da Igreja.

Com o desenvolvimento da pesquisa, percebeu-se o esforço de alguns santuários tidos como fabricados em manterem a imagem de complexos suficientes capazes de cumprir com sua função religiosa: é o caso do santuário de Fátima em Campina Grande do Sul, Paraná, ou mesmo o santuário de Fátima, em Lages, Santa Catarina. Isso não significa que os mesmos atingem tal objetivo, pois sem uma estratégia de atração e motivação às peregrinações não há possibilidade de caracterização de santuário. Ou seja, mesmo com uma infraestrutura suficiente, porém sem uma motivação simbólica, mística, que resulte em peregrinações, a possibilidade de sucesso do santuário se compromete. Afinal, sem peregrinos não há santuário. Em alguns casos, esse apelo místico é trazido ou transportado de outros santuários, normalmente santuários nacionais ou internacionais, ou seja, de grande representatividade e relevância: é o caso dos santuários dedicados a Nossa Senhora Aparecida. Como exemplo, o santuário de Aparecida de Astorga, no Paraná, que tinha como santo padroeiro São Sebastião e viu a necessidade de substituição por Nossa Senhora Aparecida para assim reduzir o deslocamento de astorganos até a Catedral de Aparecida, no estado de São Paulo. Com isso, possibilitou-se a permanência de fiéis locais na cidade e tornou-se um ponto de atratividade de peregrinos devotos da região à referida santa.

Como fomentação à criação dos santuários analisados em campo, independente de sua condição, se fabricado ou oficial comum, doações e recursos próprios foram as formas mais destacadas. Já no caso de sua manutenção no tempo e no espaço, doações, dízimo e recursos oriundos das festividades do padroeiro ou da padroeira foram as formas mais apresentadas. Ressalta-se que no caso dos santuários fabricados, a inexistência de peregrinos diminui a participação de recursos oriundos das festividades do/da padroeiro/padroeira. Nos casos dos santuários fabricados em que se realiza festa dedicada ao santo protetor, a participação de fiéis centra-se sobre a população local, por isso não se arrecada tanto recurso nesse período, caso do santuário Nossa Senhora de Fátima em Lages, Santa Catarina, cabendo, assim, ao dízimo e as doações fomentarem sua existência e resistência no tempo e no espaço. A pesquisa mostrou também que a qualidade do santuário está diretamente relacionada ao impacto que irá causar em seu espaço de abrangência e de entorno. O espaço geográfico construído ou modificado pelas atividades do santuário liga-se à atividade do turismo religioso, ao comércio de artigos religiosos, ao movimento de peregrinos e demais participantes; pode refletir na construção, adequação e/ou revitalização de estruturas

$\begin{array}{lllll}\text { Caminhos de Geografia } \quad \text { Uberlândia-MG } & \text { v. 21, n. } 78 \quad \text { Dez/2020 } & \text { p. 36-47 } & \text { Página } 45\end{array}$ 
públicas, como praças e estacionamentos por parte da administração da cidade, seja por pedido direto da instituição santuário ou não. O que se deixa claro é que é o movimento de peregrinos que impulsiona tais medidas, pois sem peregrinos não há vida de santuário: não se firma conceitualmente e nem se justifica na prática, caso dos santuários fabricados. Não há participação efetiva dos santuários fabricados na economia da cidade lócus e sua principal função, a peregrinação, bem como os demais elementos geográficos de definição de santuário, é ínfima.

\section{CONSIDERAÇÕES FINAIS}

Para checar ao conceito de santuário fabricado foram analisados em campo e em gabinete a aplicabilidade dos santuários estudados junto aos conceitos variados de santuário desenvolvidos ao longo do tempo por diversos autores. Muitos destes conceitos coincidem uns com os outros enquanto outros se complementam. Como resultado desse agrupamento de conceitos, produziu-se os critérios de definição de santuário, o que culminou no surgimento do conceito de santuário fabricado, uma tentativa de explicação de estruturas estranhas aos santuários tidos como oficiais comuns perante a Igreja Católica.

Há espaços sacroprofanos interdependentes (LIMA, 2016) que fogem totalmente do padrão conceitual usual na academia, espaços sem infraestrutura adequada, sem peregrinações e sem elementos considerados fundamentais a sua manutenção no tempo e no espaço como santuário, fugindo, inclusive, da conceituação do próprio código do direito canônico católico. A impressão que se tem é de que não há uma rigidez, por parte dos agentes do sagrado, em promover a emancipação de espaços sagrados em santuário, podendo ocorrer pelo simples desejo unilateral de um pároco; por motivação popular; por interesse político associado à ideia de turismo (setor econômico), o que poderia resultar em um maior investimento em infraestrutura do entorno e do próprio complexo ao cumprimento das atividades do sagrado, mas podendo funcionar apenas como verniz, interessante à vista, mas sem o conteúdo sacro esperado; por apelo místico em que um(a) santo(a) é tido(a) como provedor(a) de milagres e elemento significante de atração de peregrinos; de forma natural, ampliando-se com o passar do tempo, muito em função da participação e visitação de fiéis romeiros/peregrinos; ou mesmo por necessidade de reforma do santuário onde, por improviso, enquanto se investe em uma infraestrutura adequada ao local, um espaço insuficiente toma signicamente a forma de santuário, como é o caso do anexo do Santuário de Fátima de Campina Grande do Sul, Paraná. Estes foram os fatores encontrados nesta pesquisa à elevação de estruturas sagradas em espaços sacroprofanos interdependentes, sejam eles oficiais comuns ou fabricados. Espera-se, assim, que com esse artigo, mas, sobretudo, com a tese que será defendida em breve, seja possível aprofundar a discussão acerca dessas variações e assim identificar conceitualmente os santuários fabricados em tipologia específica, sendo o santuário fabricado um santuário oficial, portanto reconhecido pela Igreja Católica, porém desprovido da maioria dos critérios de definição de santuário, especialmente do critério de peregrinação, não cumprindo, portanto, com sua função religiosa.

O conceito de Santuário Fabricado desenvolvido na tese da qual este artigo está embasado, bem como a metodologia utilizada à análise desses espaços sacroprofanos interdependentes podem ser aplicadas a outras realidades para além da região sul do país a fim de constatar a ocorrência desses complexos e suas divergências com os chamados santuários oficiais comuns e, assim, promover analogias com outros levantamentos de mesmo tema.

\section{AGRADECIMENTOS}

A fundação Coordenação de Aperfeiçoamento de Pessoal de Nível Superior - CAPES, pela concessão de bolsa de estudos de doutoramento, essencial à manutenção financeira de minha pesquisa, em especial durante trabalho de campo.

\section{REFERÊNCIAS}

ELIADE, Mircea. O Sagrado e o Profano: A essência das religiões. São Paulo: Martins Fontes, 1992. FRANÇA, M. Cecília. Pequenos Centros Paulistas de Função Religiosa. São Paulo: IG/USP, 1975.

GIL, A. C. Métodos e técnicas de pesquisa social. 6. ed. São Paulo: Atlas, 2008. 
LIMA, F. J. L. A. P. "Canindé é quando dé": trabalho e recompensa. Dissertação (Mestrado em Geografia). Programa de Pós Graduação em Geografia - PGE, Universidade Estadual de Maringá UEM. Maringá, 2016.

PEREIRA, J. C. A Linguagem do Corpo na Devoção Popular do Catolicismo. Revista de Estudo da Religião, no-3, 2003, p. 67-98.

ROSENDHAL, Z. Espaço e Religião: Uma abordagem geográfica. Rio de Janeiro: UERJ, NEPEC, 1996. 92p.

. Hierópolis: O Sagrado e o Urbano. Rio de Janeiro: EDUERJ/NEPEC, 1999.

. O Sagrado e o Espaço. In: Explorações geográficas: percursos no fim do século. (Org.) CASTRO, I. E. de; GOMES, P. C. da C; CORRÊA, R. L. Rio de Janeiro: Bertrand Brasil, 1997, p.119154.

. O Sagrado e o Urbano: Gênese e Função das Cidades. In: ROSENDAHL, Z. Hierópolis: O Sagrado e o Urbano. Rio de Janeiro: EDUERJ/NEPEC, 1999, p. 13-38.

RUBERT, H. A. A vida litúrgica nos Santuários. Roma: Pontifício Ateneo Santo Anselmo. Instituto Litúrgico, 1987.

SANTOS, M. da G. M. P. Conhecimento Geográfico e Peregrinações: contributo para uma abordagem teórica. In: (Org.) ROSENDAHL, Z. Trilhas do Sagrado. Rio de Janeiro: EdUERJ, 2010, p. 145-188.

SANTOS, M. da G. M. P. Os Santuários como lugares de construção do sagrado e de memória hierofânica: esboço de uma tipologia. In: (Org.) ROSENDAHL, Z.; CORREA, R. L. Espaço e Cultura: Pluralidade Temática. Rio de Janeiro: EdUERJ, 2008.

SOUZA, M. L. de. ABC do desenvolvimento urbano. Ed. 2. Rio de Janeiro: Bertrand Brasil, 2005.

VATICANO. Código de Direito Canônico. Disponível em: <http://www.vatican.va/archive/cod-iuriscanonici/portuguese/codex-iuris-canonici po.pdf>. Acesso em 10 de Novembro de 2017.

Recebido em: 17/02/2020

Aceito para publicação em: 19/10/2020 